\title{
Development of a mouse model of menopausal ovarian
}

\section{cancer}

\section{Elizabeth R. Smith ${ }^{1}$, Ying Wang ${ }^{1+}$ and Xiang-Xi $X u^{1,2 *}$}

${ }^{1}$ Department of Cell Biology, Sylvester Comprehensive Cancer Center, University of Miami School of Medicine, Miami, FL, USA

${ }^{2}$ Department of Obstetrics and Gynecology, University of Miami School of Medicine, Miami, FL, USA

\section{Edited by:}

Elise Kohn, National Cancer Institute, USA

\section{Reviewed by:}

Reuven Reich, Hebrew University of Jerusalem, Israel

Barbara Vanderhyden, University of Ottawa, Canada

Louis Dubeau, University of Southern California, USA

\section{${ }^{*}$ Correspondence:}

Xiang-Xi Xu, Departments of Cell

Biology, Obstetrics and Gynecology, UM/Sylvester Comprehensive Cancer

Center, University of Miami School of Medicine, Miami, FL 33136, USA

e-mail: xxu2@med.miami.edu

\section{${ }^{\dagger}$ Present address:}

Ying Wang, Department of Medicine, University of California at San Diego, La Jolla, CA 92093, USA
Despite significant understanding of the genetic mutations involved in ovarian epithelial cancer and advances in genomic approaches for expression and mutation profiling of tumor tissues, several key questions in ovarian cancer biology remain enigmatic: the mechanism for the well-established impact of reproductive factors on ovarian cancer risk remains obscure; cell of origin of ovarian cancer continue to be debated; and the precursor lesion, sequence, or events in progression remain to be defined. Suitable mouse models should complement the analysis of human tumor tissues and may provide clues to these questions currently perplexing ovarian cancer biology. A potentially useful model is the germ cell-deficient WV (white spotting variant) mutant mouse line, which may be used to study the impact of menopausal physiology on the increased risk of ovarian cancer. The Wv mice harbor a point mutation in c-Kit that reduces the receptor tyrosine kinase activity to about $1-5 \%$ (it is not a null mutation). Homozygous Wv mutant females have a reduced ovarian germ cell reservoir at birth and the follicles are rapidly depleted upon reaching reproductive maturity, but other biological phenotypes are minimal and the mice have a normal life span. The loss of ovarian function precipitates changes in hormonal and metabolic activity that model features of menopause in humans. As a consequence of follicle depletion, the Wv ovaries develop ovarian tubular adenomas, a benign epithelial tumor corresponding to surface epithelial invaginations and papillomatosis that mark human ovarian aging. Ongoing work will test the possibility of converting the benign epithelial tubular adenomas into neoplastic tumors by addition of an oncogenic mutation, such as of Tp53, to model the genotype and biology of serous ovarian cancer. Model based on the Wv mice may have the potential to gain biological and etiological insights into ovarian cancer development and prevention.

Keywords: ovarian cancer, epithelium, menopause, mouse models, ovarian follicles, pre-malignant lesions, Tp53

\section{INTRODUCTION}

Most ovarian cancers are epithelial-derived, and of the four major histological subtypes, serous ovarian cancer accounts for approximately $70 \%$ of the tumors $(1-4)$. Serous ovarian carcinomas usually present as high-grade, with limited therapy options (57). Standard treatment regimens involve surgery to remove all visible disease, followed by a combination of taxane and platinumbased chemotherapy. Most patients who respond to first line chemotherapy will eventually relapse and die from drug-resistant disease. Despite intensive research and improvements in surgery and chemotherapy, the 5-year survival rate for ovarian cancer patients has languished around $30 \%$ for the past 30 years (57). This dismal survival rate attests to the urgency for a clear, more accurate understanding of basic ovarian cancer biology and etiology.

In the last several decades, great effort has been devoted to understanding ovarian cancer and the research has yielded significant knowledge and information about the biology and genetics of the disease (1-4). BRCA1 and BRCA2 mutations are associated with hereditary breast and ovarian cancers (1-4), which account for only a small fraction (estimated to be around 5-10\%) of ovarian cancer cases. Recently, the Cancer Genome Atlas Project has provided a molecular profile of serous cancers (8): the tumor suppressor Tp53 is frequently mutated, but no other somatic mutation is consistently or frequently found. Nevertheless, Tp 53 deletion alone is insufficient to induce epithelial tumors in mouse models (9-14). Thus, the molecular mechanism of ovarian serous cancer is not completely understood. In all the many types of ovarian tumor mouse models published so far, none reflects both the genetic ( $\mathrm{p} 53$ mutation) and serous histology of human cancer.

Another key question in ovarian cancer biology related to reproductive etiology remains unanswered (1-4). Reproductive factors, such as increased parity and use of oral contraceptives, reduce the risk of ovarian cancers. Age and menopausal statues are even more important factors in ovarian cancer risk (1-4). Most ovarian cancers are diagnosed in menopausal women; fewer than $15 \%$ are diagnosed in women younger than 50 years of age, and the histological subtype of those cancers may not be epithelial but derived from germ cells or granulosa cells (15). The risk of ovarian 
cancer increases greater than fivefold during the peri-menopausal years (16-23).

In laboratory studies, few of the developed ovarian tumor models incorporate the epidemiological evidence that reproductive factors and age influence the risk of ovarian cancer. Consequently, the mechanism for the well-established impact of reproductive factors on ovarian cancer risk remains obscure and not well explored. Thus, a reasonably good model to understand the etiology of ovarian cancer should incorporate the genetics and the reproductive physiology of the disease, such as menopausal stage. Here, we discuss the development of a unique mouse model to study menopausal ovarian cancer.

\section{OVARIAN CANCER EPIDEMIOLOGY AND ETIOLOGY}

Epidemiological evidence suggests that the risk of ovarian cancer associates with reproductive history and hormonal factors (16$23)$. Increased parity decreases the risk by $50 \%$ over nulliparity, as does oral contraceptive use for 5 years $(17,19,20)$. The most significant risk factors for developing ovarian cancer are age and menopausal status (16-23). The majority of ovarian cancers are diagnosed in post-menopausal women in their late 50s and early 60s. The average age of diagnosis for sporadic ovarian cancer is about 63 years, although women with genetic or familial risk factors tend to be diagnosed at a younger age (average age of diagnosis is 54 years). Thus, it appears that age and menopausal status closely associate with ovarian cancer risk.

Several theories have been proposed to explain the epidemiological data associated with ovarian cancer risk. One idea holds that incessant ovulation, or the repeated wounding and subsequent proliferation that occur to repair the surface epithelium at the site of ovulation, results in mutations accumulating in the ovarian surface epithelial cells (24-26). Ultimately a tumor mass develops. This idea would explain the reduction of risk associated with pregnancy, extended breastfeeding, some oral contraceptive formulations, and early menopause, all of which reduce the number of ovulatory events.

Supported by the same epidemiological evidence, the gonadotropin stimulation hypothesis postulates that the surges of pituitary gonadotropins [including follicle stimulating hormone (FSH) and luteinizing hormone (LH)] that initiate each ovulation also stimulate the ovarian surface epithelium and induce cell transformation $(20,21)$. The speculated role of gonadotropins is also consistent with the fact that ovarian cancer occurs most frequently in post-menopausal women, when ovulation ceases yet plasma gonadotropins are elevated (21-23). However, since FSH and $\mathrm{LH}$ have unremarkable effects on growth of ovarian surface epithelial cells in culture (27-29), a direct effect of the hormones on ovarian epithelial transformation is unlikely to be sufficient. Thus, neither theory completely or satisfactorily explains the epidemiological observation of an association between ovarian cancer incidence and the menopausal transition.

A more recent idea posits that the depletion of ovarian follicles disrupts ovarian epithelial homeostasis and may be the true cause of an increased cancer risk in menopause (30). The idea that loss of ovarian function may underlie the link between reproductive factors and ovarian cancer was also proposed previously (31). The follicle depletion hypothesis explains the association between menopause and ovarian cancer risk, and can potentially unify "incessant ovulation" and "gonadotropin stimulation" as mechanisms. Specifically, incessant ovulation leads to the depletion of the ovarian reserve, which in turn leads to the increased level of gonadotropins that characterize menopause. Thus, the two theories explain the cause and consequence, respectively, of ovarian follicle depletion. The studies of a germ cell-deficient $\mathrm{Wv}$ mouse line provided basis for the follicle depletion theory $(30,31)$.

\section{BIOLOGY OF MENOPAUSE}

By the end of the reproductive age, germ cells and follicles are depleted from the ovaries and the ovulatory cycle ceases, resulting in menopause. Menopause is defined as the permanent cessation of menstruation resulting from depletion of germ cells and loss of ovarian follicular activity (32-34), and has become a woman's health issue as a by-product of modern health advances and the extension of lifespan that occurred in the last century (32-34). The peri-menopausal period commences when the first features of menopause begin until at least 1 year after the final menstrual period, generally lasting an average of 5 years. In humans, the transition to menopause is a set of gradual changes, in which ovarian function, reproductive capacity, and hormonal status are altered long before menses stops completely. Menopause generally occurs between 45 and 55 years of age, and the symptoms vary among women.

Hormonal changes characterize the menopausal transition. In the normal reproductive ovary, following ovulation and release of the ovum, the follicle converts into a corpus luteum, where sex steroids, predominately estrogen and progesterone, are produced and released. The steroid hormones act to inhibit the release of FSH and LH. With the depletion of follicles and cessation of ovulation, estrogen and progesterone levels fall and normal feedback inhibition of FSH and $\mathrm{LH}$ release stops. As a result, FSH and $\mathrm{LH}$ reach highest serum levels in peri- and post-menopausal periods and remain elevated (32-34). These changes precipitate a number of menopausal-associated symptoms and disorders.

\section{MECHANISMS FOR MENOPAUSE AS A RISK FACTOR}

Among the physiological changes associated with menopause, the ovarian tissues undergo morphological transformation, known as "ovarian aging" (25), and this is implicated in the high incidence of ovarian cancer that occurs during the peri-menopausal and immediate post-menopausal periods $(30,31)$. One feature associated with ovarian aging is the accumulation of ovarian morphological changes such as deep invaginations, surface papillomatosis, and inclusion cysts (35-37), which are thought by some to be the histological precursors of ovarian cancer (38-43). Presumably, acquisition of an oncogenic mutation (such as Tp53 mutation) in these proliferative ovarian epithelial cells would promote the development of ovarian cancer.

From the analysis of pre-cancerous ovarian tissues obtained from prophylactic oophorectomies, pre-neoplastic lesions and microscopic carcinomas were identified in the ovaries or fimbria of fallopian tubes from women with a family history of ovarian cancer or identified BRCA mutations $(38,44,45)$. Several studies reported the increased ovarian morphological changes in highrisk ovaries $(35,37,38,46,47)$, though some found negative results 
(48-50). In one analysis, we found that no significant increase in the presence of non-neoplastic ovarian morphological changes is associated with BRCA1/BRCA2 mutations (35). Rather, the frequency of these histological features, especially inclusion cysts, associates with age or menopausal status. We propose that ovarian morphological changes increase in the peri-menopausal period, and these histological features may promote the transformation of genetically compromised epithelial cells in the development of ovarian cancer. The results suggest age-dependent pre-neoplastic morphological changes may be a risk factor, and support the idea that ovarian aging-related epithelial morphological changes provide precursor cells that may transform upon acquisition of oncogenic mutation(s) (42).

The fallopian tube origin of ovarian cancer suggests that tubal epithelial cells from the normal fimbria, which envelops the ovary and contacts the ovarian surface, dislodge and seed, or implant on, the surface of the ovary (51-58). Inclusion cysts form by membrane engulfment. Likewise, transformed cells of the fimbria may shed and implant on the ovarian surface. The tumor that establishes appears to arise from the ovary but originates, in fact, from the fallopian tube. It may be that age and follicle depletion alter the receptivity of the ovarian surface to seeding by the fallopian fimbria epithelial cells, i.e., its ability to accept the fimbria cells, and also make it a more permissive substratum for engulfment or proliferation of the seeded cells. Thus, the idea of follicle depletion as a risk factor for ovarian cancer may also be adapted to the fallopian tube cell of origin model, in addition to that originally proposed considering only cancer derived from the ovarian surface and/or surface-derived inclusion cysts $(30,31)$. Additionally, follicle depletion may also encourage the proliferation of stromal epithelial cells of Müllerian origin, which have also been considered to be possible cells of origin of ovarian serous carcinomas (59, 60). The epithelial cells of both fallopian tube fimbria and extraovarian Müllerian glands may be responsive to the menopausal increase of gonadotropins.

\section{MOUSE MODELS IN OVARIAN CANCER RESEARCH}

In the past decade, a number of technical breakthroughs have led to the establishment of several mouse models as described briefly here. First, a genetically defined model of ovarian cancer was established by Orsulic and colleagues (13), in which mouse ovarian surface epithelial cells were isolated and transfected with defined genetic changes such as k-Ras, v-Akt, v-myc, etc. The cells were then re-implanted into the ovarian bursa of mice and malignant ovarian tumors developed. Using the MIS II R promoter, a mainly ovarian-restricted transcript, Connolly, Hamilton and colleagues developed the T-antigen transgenic line that develops malignant bilateral ovarian tumors (61). Presumably, T-antigen expression results in the inactivation of both p53 and Rb. Indeed, using adenoviral delivery of cre to ovaries of mice with floxed p53 and Rb, Flesken-Nikitin et al. demonstrated the development of malignant ovarian tumors when both p53 and $\mathrm{Rb}$ are deleted (11). Mice with conditional expression of K-ras and deletion of pten in ovarian surface epithelial cells were made and found to develop endometriosis and endometrioid carcinomas (62). Since both mutations are associated with endometriosis and endometrioid ovarian cancer in humans, this model appears to recapitulate the genotype and histomorphology of the human disease. Another mouse model of endometrioid carcinomas was established by combining beta-catenin activation and pten loss (63). Based on the understanding that the majority of serous ovarian cancer may be derived from fallopian tube fimbria, the reproductive tract tumor models were produced by targeting SV40T using the promoter of the mouse oviduct-specific glycoprotein (OGP) (64). In another study, fallopian tube-derived tumors were produced by Amhr2Cre mediated deletion of pten and Dicer (65). Likely there are additional ovarian cancer animal models that are not mentioned here (66-69).

However, the modeling of genotype and phenotype of human serous cancer has not been successful. Although p53 mutation is the only common genetic mutation in ovarian cancer (8), p53 null mice do not develop ovarian cancer. When p53 null ovaries were transplanted into wild type mice to allow prolonged aging, the tumors that developed were of granulosa rather than epithelial origin (9). In several recent studies, concomitant inactivation of Tp53 and BRCA1 produced leiomyosarcomas, which likely originated from the ovarian bursa $(10,12-14)$. Further investigation of these animal models should lead to a better, more thorough understanding of ovarian cancer development. Nevertheless, none of these models has components related to the etiology of ovarian cancer. Also, few investigations on early lesions or cells of origins were reported in these ovarian tumor models.

To investigate reproductive factors, mouse models that mimic or incorporate menopausal biology may be useful. Most female mammals, except for humans, live only a relatively short time after ceasing reproduction, and normal rodents or other animals do not adequately model the menopausal state (32). In the laboratory setting, surgical removal of ovaries is used to mimic menopause on the physiology. Another method is to kill germ cells and ovarian follicles using toxins such as such as busulfan and 4-vinylcyclohexene diepoxide (70-72). These "menopausal mouse models" may be useful for some purposes, for example, to investigate breast tumor xenografts under menopausal conditions and to study chemical-induced breast carcinogenesis (73, 74). Mutant mice that contain gene mutation affecting ovarian function were also suitable to investigate ovarian cancer. A notable mouse model of restricted BRCA1 deletion in granulose cells was produced to investigate the association between menstrual cycle and ovarian cancer risk $(75,76)$. Mice with FSH receptor knockout were reported to exhibit some phenotype of ovarian failure and have been proposed as a potential model of menopause (77). In this article, we highlight the use of a natural mutant mouse line, the white spotting variant $(\mathrm{Wv})$ mouse, to model menopause and associated ovarian cancer risk. In the Wv females, the ovarian follicles are gradually depleted early in life because of a reduced c-kit activity and resulted oocyte reserve, and the mice mimic the phenotypes in both the cause (ovarian follicle depletion) and many consequences (such as changes in heart, bone, lipids, ovarian epithelia) of menopause $(78,79)$.

\section{THE Wv GERM CELL-DEFICIENT MOUSE MODELS}

The Wv mice harbor a point mutation in the kinase domain of the c-kit gene, resulting in developmental defects in germ cells, pigment-forming cells, red blood cells, and mast cells in 
homozygous mutant mice (68-83). The Wv/Wv mice have a similar lifespan as wild type, are sterile, white-coated with black eyes, and predisposed to ovarian neoplasms (84). The $\mathrm{Wv} / \mathrm{Wv}$ mice contain less than $5 \%$ of the normal number of oocytes at birth and the remaining germ cells are depleted by about 8 weeks of age (Figure 1). Consequently, ovulation ceases to occur and an increase in pituitary gonadotropins follows (85). Compared to wild type littermates, in which ovaries contain a large number of follicles at various developmental stages, $\mathrm{Wv}$ ovaries are depleted of follicles by 2-3 months of age (Figure 1). Ovarian surface epithelial dysplasia and tubular adenomas develop in $\mathrm{Wv} / \mathrm{Wv}$ mice $(79,85)$. The Wv mice appear to model several aspects of postmenopausal biology, including a long post-reproductive lifespan, increased serum gonadotropins, decreased sex steroids, and physiological changes, such as decreased bone density, elevated serum cholesterol, and altered cardiac function (78).

The ovarian lesions in the $\mathrm{Wv}$ mice distribute throughout the ovarian stroma, and are known as stromal tubular adenomas (85). The contiguous connection to ovarian surface epithelium is evident (Figure 2), and is especially pronounced in early ovarian lesions from younger (7-10 weeks) mice when lesions begin to develop (79). The majority if not all the tubular adenomas in $\mathrm{Wv} / \mathrm{Wv}$ ovaries appear to be derived from ovarian surface epithelial cells. However, rete ovarii structure is also very prominent in Wv ovaries. At 4 months, epithelial lesions permeate the entire ovary, and rete ovarii appear to form distinct lesions (Figure 2, arrow). At 8 months of age, the $\mathrm{Wv}$ ovarian tumor is extensive, and surface versus rete ovarii epithelia are no longer distinguishable. The majorities of the lesions either exhibit inclusion cyst-like structures or resemble surface deep invaginations/papillomatosis (Figure 2) (79).

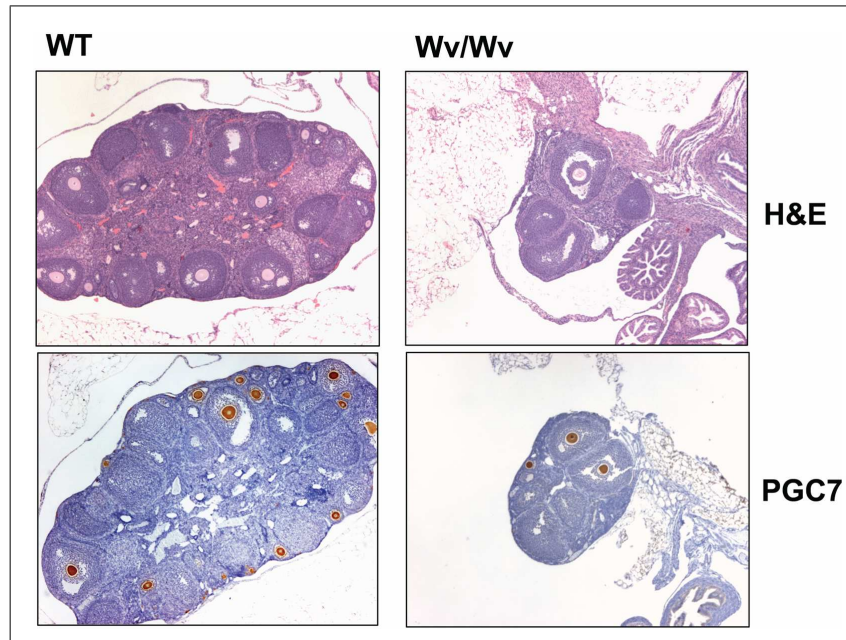

FIGURE 1 | Germ cell deficiency in Wv ovaries. Ovaries from 6-week-old wild type and WvMv littermates were harvested and subjected to histological analysis. PGC7 staining was used as a marker for germ cells and follicles $(86,87)$. Wild type ovaries contain abundant PGC7-positive germ cells and follicles of various developmental phases, and in particular, germ cells and primary follicles are found immediately beneath the surface. WvMv mutant ovaries are smaller and contain a greatly reduced number of germ cells.

\section{POTENTIAL DEVELOPMENT OF THE Wv MICE TO MODEL MENOPAUSAL OVARIAN CANCER}

The germ cell-deficient $\mathrm{Wv}$ mutant mouse line mice may be explored to gain additional understanding and verification of the impact of menopausal physiology on the increased risk of ovarian cancer.

Tp53 deletion, alone or in combination with other genetic changes, does not seem to produce ovarian epithelial tumors in mouse models. Since mutations in Tp53 that result in accumulation of mutated $\mathrm{Tp} 53$ protein occur frequently in ovarian cancer and are more relevant than deletion $(8,88)$, it may be possible to add the Tp53 mutation in the Wv ovarian tubular adenomas to test if Tp53 mutation can convert the benign epithelial tumors to malignant adenocarcinomas (Figure 3). If successful, such a

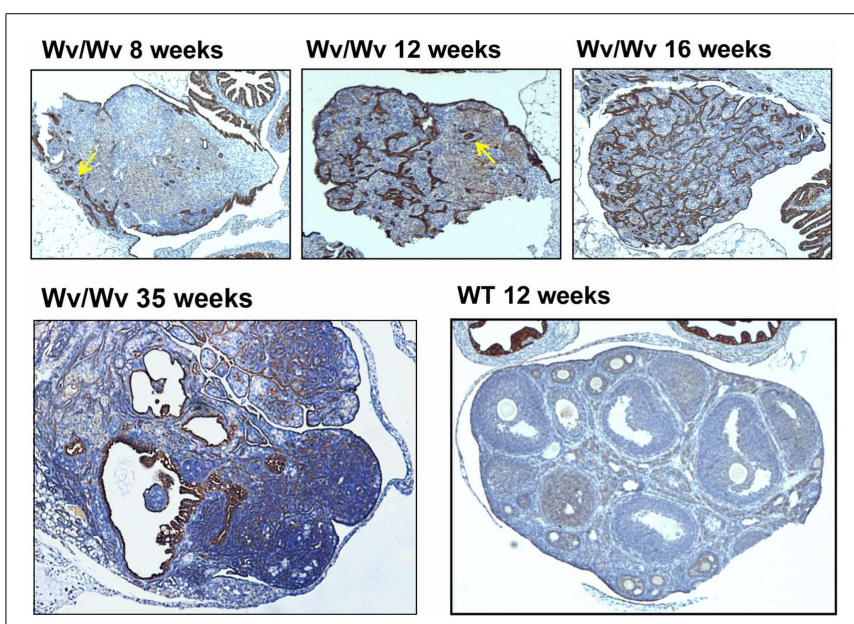

FIGURE 2 | Epithelial ovarian tumors in Wv/Wv mice. Ovarian tissues were harvested and subjected to histological analysis. Cytokeratin-8 staining was used as a marker for epithelial cells. Representative ovaries are shown for 8-, 12-, 16-, and 35-week-old WvMv mice, indicating the progressive increase in epithelial lesions. In comparison, a wild type ovary from a 16-week-old littermate has a single layer of cytokeratin-8-positive ovarian surface epithelium. The arrows in the two left panels indicate the putative lesions that developed from rete ovarii.

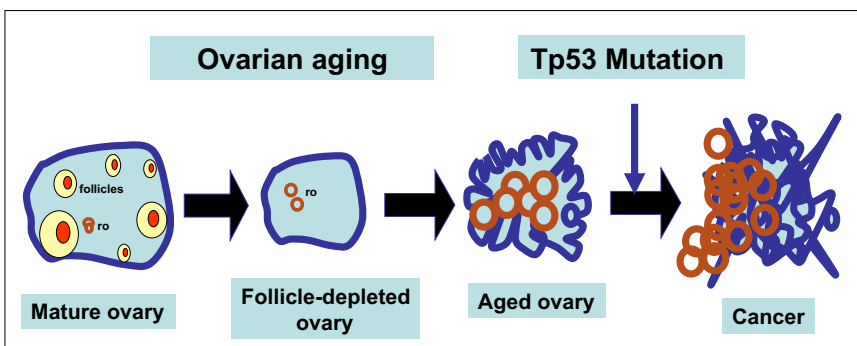

FIGURE 3 | Working model for follicle depletion and ovarian aging in ovarian tumorigenesis. A schematic illustration of the consequences of follicle depletion in the development of ovarian tumors is presented. Upon depletion of ovarian follicles, ovarian surface and rete ovarii (ro) epithelia undergo remodeling and morphological changes. Wv ovarian epithelial tumors may be derived from both surface and rete ovarii (ro). Genetic mutations, such as Tp53 mutation, will promote the benign epithelial lesions to develop into malignant tumors. 
model may mimic the development epithelial ovarian cancer in both genetic and reproductive aspects. Using the $\mathrm{Wv}$ mice, we are currently performing experiments to determine if adding a Tp53 point mutation in the epithelial cells of the $\mathrm{Wv}$ ovarian tumor generates a malignant tumor that resembles ovarian cancer.

By deleting a transcription stop signal in the floxed Tp53 mutant (88) in ovarian surface epithelial cells through injection of adenovirus expression Cre, we predict that the model mimics both reproductive factors (postmenopause) and genetic mutation (Tp53). Preliminary studies indicate that these Wv/Wv:p53(R172H) (fl/fl):Adv-Cre ovarian epithelial tumors appear malignant. We are currently characterizing in more detail these mouse ovarian epithelial models and expect to report these findings in the near future.

\section{POSSIBLE STRATEGIES FOR DELAYING MENOPAUSE AND OVARIAN CANCER RISK REDUCTION}

The neoplastic ovarian tumor models following addition of Tp53 mutation in the benign Wv tumors may be used to explore several questions regarding the etiology and possible preventive strategies for ovarian cancer. Several potential preventive approaches, such as inhibition of cyclooxygenases and use of progestin to mimic oral contraceptive usage, have been proposed and can be tested in Wv mouse models.

Genetic suppression of cyclooxygenase 2 produced a significant alleviation of ovarian lesions in the Wv/Wv:Cox-2 ( \pm ) ovaries analyzed, although the degree to which the tumor phenotype was suppressed varied greatly (79). Hemizygous reduction of the Cox-2 gene resulted in a complete or partial rescue from the epithelial adenoma phenotype. Thus, a reduction in Cox- 2 gene dosage rescued the ovarian epithelial morphological alteration, but deletion of both copies was less sufficient in reversing the adenoma phenotype. Reducing the Cox-2 gene dosage on ovarian tumor phenotype can be achieved by using pharmacological agents. Thus, cyclooxygenase inhibitors are able to prevent ovarian epithelial morphological transformation and tumor phenotypes. Inhibition of both Cox- 1 and Cox-2 with indomethacin is more effective than inhibition of Cox-2 alone with celebrex. When indomethacin was given for a period of 1 month to $\mathrm{Wv} / \mathrm{Wv}$ mice at 3 months of age when ovarian tumors were already established, the tumors were not reduced compared to controls, suggesting inhibition of cyclooxygenases prevents the development of ovarian tumors but has no suppressive effect on established tumors (79). Furthermore, inhibition of Cox-1 was superior to inhibition of Cox-2, and inhibition of Cox-1 reduced the development of ovarian adenomas in $\mathrm{Wv}$ mice by delaying ovarian follicle maturation and thus depletion (89) occurs. The conclusions of these studies are consistent with the notion that the ovarian follicle depletion, rather than ovulation and gonadotropin stimulation, is a major determinant of an increased ovarian cancer risk in menopause. The experimental results provide explanation for the epidemiological observations that use of non-steroidal anti-inflammatory drugs (NSAIDs) reduce ovarian cancer risk (90-96). Inhibition of Cox-1 and Cox-2 may have different mechanisms. Cox-1 inhibition may delay follicle depletion and ovarian cancer risk. Cox-2 inhibitors may reduce the cancer promoting activity of the inflammationlike ovulatory processes that are stimulated by gonadotropins (95,
96). The mechanism predicts that use of NSAIDs may be more effective in reducing the risk of ovarian cancer in pre-menopausal compared to post-menopausal women, since Cox-1 inhibition can delay ovarian follicle depletion (89). In post-menopausal women, inhibition of Cox-2 may slow epithelial remodeling and thus still reduce ovarian cancer risk.

Because endogenous hormones play a major role in the risk of breast, endometrial, and ovarian cancer, the impact on risk for oral contraceptives and hormonal therapy given at about the time of menopause has been a major concern $(97,98)$. Numerous studies provide insights into cancer risk associated with use of these preparations. Generally, use of oral contraceptives reduces ovarian cancer risk $(19,99)$. Many studies attribute the preventive effect on its suppression of gonadotropin level and ovulation. Also, this risk reduction may differ between pre- and post-menopausal women. Recent studies suggest that prolonged oral contraceptive pill use provided a greater protective effect against pre-menopausal ovarian cancer than against post-menopausal cancer (100). Furthermore, suppression of pituitary gonadotropin release with hormone replacement therapy may not reduce ovarian cancer risk in post-menopausal women $(97,100)$. These findings substantiate that intact ovarian function may be an important determinant of ovarian cancer risk, and the timing of progesterone administration may differentially alter its preventive capacity depending upon follicle reserve and menopausal status. The $\mathrm{Wv}$ mouse model will be useful in experiments to test the suppressive activity of progesterone/progestin on gonadotropin levels and the role of increased gonadotropins on ovarian tumorigenesis.

\section{ACKNOWLEDGMENTS}

The work was supported by NCI/NIH grants R01 CA095071, CA79716, and CA75389 and DOD (W81XWH-06-1-0095, Ovarian Cancer Research Program Idea Award, "A Mouse Model to Investigate Post-menopausal Biology as an Etiology of Ovarian Cancer Risk," 11/01/2005-10/31/2008) (X. X. Xu), and NIH R03CA142074, the Rivken Center for Ovarian Cancer Research, and DOD OC060605 (Elizabeth R. Smith). Studies originated at Fox Chase Cancer Center (Philadelphia, PA, USA) and were continued at the Sylvester Comprehensive Cancer Center, University of Miami Miller School of Medicine (Miami, FL, USA). Over the years, several present and previous lab members contributed work related to this project, including Drs. Robert Moore, DongHua Yang, and Wan-Lin Yang, Jennifer Smedberg, Wensi Tao, Toni Yeasky, Malgorzata Rula, and several summer work students. We thank our present and past lab members for helpful discussions and comments during the course of the work.

\section{REFERENCES}

1. Bast RC, Hennessy B, Mills GB. The biology of ovarian cancer: new opportunities for translation. Nat Rev Cancer (2009) 9:415-28. doi:10.1038/nrc2644

2. Boyd J. Whence epithelial ovarian carcinoma? Gynecol Oncol (2008) 109:161-3. doi:10.1016/j.ygyno.2008.03.016

3. Cho KR, Shih IM. Ovarian cancer. Annu Rev Pathol (2009) 4:287-303. doi:10.1146/annurev.pathol.4.110807.092246

4. Ozols RF, Bookman MA, Connolly DC, Daly MB, Godwin AK, Schilder RJ, et al. Focus on epithelial ovarian cancer. Cancer Cell (2004) 5:19-24. doi:10.1016/S1535-6108(04)00002-9

5. Bukowski RM, Ozols RF, Markman M. The management of recurrent ovarian cancer. Semin Oncol (2007) 34(Suppl 2):S1-15. doi:10.1053/j.seminoncol. 2007.03.012 
6. Alberts DS, Markman M, Muggia F, Ozols RF, Eldermire E, Bookman MA, et al. Proceedings of a GOG workshop on intraperitoneal therapy for ovarian cancer. Gynecol Oncol (2006) 103:783-92. doi:10.1016/j.ygyno.2006.09.012

7. Ozols RF. Challenges for chemotherapy in ovarian cancer. Ann Oncol (2006) 17(Suppl 5):181-7. doi:10.1093/annonc/mdj978

8. Cancer Genome Atlas Research Network. Integrated genomic analyses of ovarian carcinoma. Nature (2011) 474:609-15. Erratum in: Nature (2012) 490:298 doi:10.1038/nature10166

9. Chen CM, Chang JL, Behringer RR. Tumor formation in p53 mutant ovaries transplanted into wild-type female hosts. Oncogene (2004) 23:7722-5. doi:10. 1038/sj.onc. 1208037

10. Clark-Knowles KV, Senterman MK, Collins O, Vanderhyden BC. Conditional inactivation of Brca1, p53 and $\mathrm{Rb}$ in mouse ovaries results in the development of leiomyosarcomas. PLoS One (2009) 4:e8534. doi:10.1371/journal. pone. 0008534

11. Flesken-Nikitin A, Choi KC, Eng JP, Shmidt EN, Nikitin AY. Induction of carcinogenesis by concurrent inactivation of p53 and Rb1 in the mouse ovarian surface epithelium. Cancer Res (2003) 63:3459-63.

12. Mullany LK, Liu Z, King ER, Wong KK, Richards JS. Wild-type tumor repressor protein p53 (Trp53) promotes ovarian cancer cell survival. Endocrinology (2012) 153:1638-48. doi:10.1210/en.2011-2131

13. Orsulic S, Li Y, Soslow RA, Vitale-Cross LA, Gutkind JS, Varmus HE. Induction of ovarian cancer by defined multiple genetic changes in a mouse model system. Cancer Cell (2002) 1:53-62. doi:10.1016/S1535-6108(01)00002-2

14. Quinn BA, Brake T, Hua X, Baxter-Jones K, Litwin S, Ellenson LH, et al. Induction of ovarian leiomyosarcomas in mice by conditional inactivation of Brcal and p53. PLoS One (2009) 4:e8404. doi:10.1371/journal.pone.0008404

15. Tortolero-Luna G, Mitchell MF. The epidemiology of ovarian cancer. J Cell Biochem Suppl (1995) 23:200-7. doi:10.1002/jcb.240590927

16. Lukanova A, Kaaks R. Endogenous hormones and ovarian cancer: epidemiology and current hypotheses. Cancer Epidemiol Biomarkers Prev (2005) 14:98-107.

17. Riman T, Persson I, Nilsson S. Hormonal aspects of epithelial ovarian cancer: review of epidemiological evidence. Clin Endocrinol (Oxf) (1998) 49:695-707. doi:10.1046/j.1365-2265.1998.00577.x

18. Salehi F, Dunfield L, Phillips KP, Krewski D, Vanderhyden BC. Risk factors for ovarian cancer: an overview with emphasis on hormonal factors. J Toxicol Environ Health B Crit Rev (2008) 11:301-21. doi:10.1080/10937400701876095

19. Schildkraut JM, Calingaert B, Marchbanks PA, Moorman PG, Rodriguez GC. Impact of progestin and estrogen potency in oral contraceptives on ovarian cancer risk. J Natl Cancer Inst (2002) 94:32-8. doi:10.1093/jnci/94.1.32

20. Cramer DW, Hutchison GB, Welch WR, Scully RE, Ryan KJ. Determinants of ovarian cancer risk. I. Reproductive experiences and family history. J Natl Cancer Inst (1983) 71:711-6.

21. Mohle J, Whittemore A, Pike M, Darby S. Gonadotrophins and ovarian cancer risk. J Natl Cancer Inst (1985) 75:178-80.

22. Choi JH, Wong AS, Huang HF, Leung PC. Gonadotropins and ovarian cancer. Endocr Rev (2007) 28:440-61. doi:10.1210/er.2006-0036

23. Chiaffarino F, Pelucchi C, Parazzini F, Negri E, Franceschi S, Talamini R, et al. Reproductive and hormonal factors and ovarian cancer. Ann Oncol (2001) 12:337-41. doi:10.1023/A:1011128408146

24. Fathalla MF. Incessant ovulation - a factor in ovarian neoplasia? Lancet (1971) 2:163. doi:10.1016/S0140-6736(71)92335-X

25. Nicosia SV. The aging ovary. Med Clin North Am (1987) 71:1-9.

26. Godwin AK, Testa JR, Handel LM, Liu Z, Vanderveer LA, Tracey PA, et al. Spontaneous transformation of rat ovarian surface epithelial cells: association with cytogenetic changes and implications of repeated ovulation in the etiology of ovarian cancer. J Natl Cancer Inst (1992) 84:592-601. doi:10.1093/jnci/84.8.592

27. Ivarsson K, Sundfeldt K, Brännström M, Hellberg P, Janson PO. Diverse effects of FSH and LH on proliferation of human ovarian surface epithelial cells. Hum Reprod (2001) 16:18-23. doi:10.1093/humrep/16.1.18

28. Zheng W, Lu JJ, Luo F, Zheng Y, Feng YJ, Felix JC, et al. Ovarian epithelial tumor growth promotion by follicle-stimulating hormone and inhibition of the effect by luteinizing hormone. Gynecol Oncol (2000) 76:80-8. doi:10.1006/gyno.1999.5628

29. Huhtaniemi I. Are gonadotrophins tumorigenic - a critical review of clinical and experimental data. Mol Cell Endocrinol (2010) 329:56-61. doi:10.1016/j. mce.2010.04.028
30. Smith ER, Xu XX. Ovarian aging, follicle depletion, and cancer: a hypothesis for the etiology of epithelial ovarian cancer concerning follicle depletion. Lancet Oncol (2008) 9:1108-11. doi:10.1016/S1470-2045(08)70281-X

31. Vanderhyden BC. Loss of ovarian function and the risk of ovarian cancer. Cell Tissue Res (2005) 322:117-24. doi:10.1007/s00441-005-1100-1

32. Finn CA. Reproductive ageing and the menopause. Int J Dev Biol (2001) 45:613-7.

33. Gosden RG. Biology of Menopause: The Causes and Consequences of Ovarian Aging. Orlando: Academic Press (1985). 188 p.

34. Lobo RA, Kelsey J, Marcus R, editors. Menopause: Biology and Pathobiology. San Diego: Academic Press (2000). 672 p.

35. Cai KQ, Klein-Szanto A, Karthik D, Edelson M, Daly MB, Ozols RF, et al. Age-dependent morphological alterations of human ovaries from populations with and without BRCA mutations. Gynecol Oncol (2006) 103:719-28. doi:10.1016/j.ygyno.2006.03.053

36. Yang WL, Godwin AK, Xu XX. Tumor necrosis factor-alpha-induced matrix proteolytic enzyme production and basement membrane remodeling by human ovarian surface epithelial cells: molecular basis linking ovulation and cancer risk. Cancer Res (2004) 64:1534-40. doi:10.1158/0008-5472.CAN-032928

37. Roland IH, Yang WL, Yang DH, Daly MB, Ozols RF, Hamilton TC, et al. Loss of surface and cyst epithelial basement membranes and preneoplastic morphologic changes in prophylactic oophorectomies. Cancer (2003) 98:2607-23. doi:10.1002/cncr.11847

38. Salazar H, Godwin AK, Daly MB, Laub PB, Hogan WM, Rosenblum N, et al. Microscopic benign and invasive malignant neoplasms and a cancerprone phenotype in prophylactic oophorectomies. J Natl Cancer Inst (1996) 88:1810-20. doi:10.1093/jnci/88.24.1810

39. Scully RE. Pathology of ovarian cancer precursors. J Cell Biochem Suppl (1995) 23:208-18. doi:10.1002/jcb.240590928

40. Aoki Y, Kawada N, Tanaka K. Early form of ovarian cancer originating in inclusion cysts. A case report. J Reprod Med (2000) 45:159-61.

41. Bell DA, Scully RE. Early de novo ovarian carcinoma. A study of fourteen cases. Cancer (1994) 73:1859-64. doi:10.1002/1097-0142(19940401)73: 7<1859::AID-CNCR2820730714>3.0.CO;2-L

42. Cai KQ, Wu H, Klein-Szanto AJ, Xu XX. Acquisition of a second mutation of the Tp53 alleles immediately precedes epithelial morphological transformation in ovarian tumorigenicity. Gynecol Oncol (2009) 114:18-25. doi:10.1016/j.ygyno. 2009.03.023

43. Feeley KM, Wells M. Precursor lesions of ovarian epithelial malignancy. Histopathology (2001) 38:87-95. doi:10.1046/j.1365-2559.2001.01042.x

44. Piek JM, Torrenga B, Hermsen B, Verheijen RH, Zweemer RP, Gille JJ, et al. Histopathological characteristics of BRCA1- and BRCA2-associated intraperitoneal cancer: a clinic-based study. Fam Cancer (2003) 2:73-8. doi:10.1023/A: 1025700807451

45. Medeiros F, Muto MG, Lee Y, Elvin JA, Callahan MJ, Feltmate C, et al. The tubal fimbria is a preferred site for early adenocarcinoma in women with familial ovarian cancer syndrome. Am J Surg Pathol (2006) 30:230-6. doi:10.1097/01.pas.0000180854.28831.77

46. Werness BA, Afify AM, Bielat KL, Eltabbakh GH, Piver MS, Paterson JM. Altered surface and cyst epithelium of ovaries removed prophylactically from women with a family history of ovarian cancer. Hum Pathol (1999) 30:151-7. doi:10.1016/S0046-8177(99)90269-1

47. Leeper K, Garcia R, Swisher E, Goff B, Greer B, Paley P. Pathologic findings in prophylactic oophorectomy specimens in high-risk women. Gynecol Oncol (2002) 87:52-6. doi:10.1006/gyno.2002.6779

48. Barakat RR, Federici MG, Saigo PE, Robson ME, Offit K, Boyd J. Absence of premalignant histologic, molecular, or cell biologic alterations in prophylactic oophorectomy specimens from BRCA1 heterozygotes. Cancer (2000) 89:383-90. doi:10.1002/1097-0142(20000715)89:2<383::AID-CNCR25>3.0. $\mathrm{CO} ; 2-\mathrm{T}$

49. Casey MJ, Bewtra C, Hoehne LL, Tatpati AD, Lynch HT, Watson P. Histology of prophylactically removed ovaries from BRCA1 and BRCA2 mutation carriers compared with noncarriers in hereditary breast ovarian cancer syndrome kindreds. Gynecol Oncol (2000) 78:278-87. doi:10.1006/gyno.2000.5861

50. Seidman JD, Wang BG. Evaluation of normal-sized ovaries associated with primary peritoneal serous carcinoma for possible precursors of ovarian serous carcinoma. Gynecol Oncol (2007) 106:201-6. doi:10.1016/j.ygyno.2007.03.028 
51. Piek JM, Verheijen RH, Kenemans P, Massuger LF, Bulten H, van Diest PJ. BRCA1/2-related ovarian cancers are of tubal origin: a hypothesis. Gynecol Oncol (2003) 90:491. doi:10.1016/S0090-8258(03)00365-2

52. Crum CP. Intercepting pelvic cancer in the distal fallopian tube: theories and realities. Mol Oncol (2009) 3:165-70. doi:10.1016/j.molonc.2009.01.004

53. Kurman RJ, Shih IeM. The origin and pathogenesis of epithelial ovarian cancer: a proposed unifying theory. Am J Surg Pathol (2010) 34:433-43. doi:10.1097/PAS.0b013e3181cf3d79

54. Kurman RJ, Shih IeM. Molecular pathogenesis and extraovarian origin of epithelial ovarian cancer - shifting the paradigm. Hum Pathol (2011) 42:918-31. doi:10.1016/j.humpath.2011.03.003

55. Lee Y, Miron A, Drapkin R, Nucci MR, Medeiros F, Saleemuddin A, et al. A candidate precursor to serous carcinoma that originates in the distal fallopian tube. J Pathol (2007) 211:26-35. doi:10.1002/path.2091

56. Folkins AK, Saleemuddin A, Garrett LA, Garber JE, Muto MG, Tworoger SS, et al. A candidate precursor to pelvic serous cancer (p53 signature) and its prevalence in ovaries and fallopian tubes from women with BRCA mutations. Gynecol Oncol (2008) 109:168-73. doi:10.1016/j.ygyno.2008.01.012

57. Shaw PA, Rouzbahman M, Pizer ES, Pintilie M, Begley H. Candidate serous cancer precursors in fallopian tube epithelium of BRCA1/2 mutation carriers. Mod Pathol (2009) 22:1133-8. doi:10.1038/modpathol.2009.89

58. Li J, Fadare O, Xiang L, Kong B, Zheng W. Ovarian serous carcinoma: recent concepts on its origin and carcinogenesis. J Hematol Oncol (2012) 5:8. doi:10.1186/1756-8722-5-8

59. Dubeau L. The cell of origin of ovarian epithelial tumors and the ovarian surface epithelium dogma: does the emperor have no clothes? Gynecol Oncol (1999) 72:437-42. doi:10.1006/gyno.1998.5275

60. Dubeau L. The cell of origin of ovarian epithelial tumours. Lancet Oncol (2008) 9:1191-7. doi:10.1016/S1470-2045(08)70308-5

61. Connolly DC, Bao R, Nikitin AY, Stephens KC, Poole TW, Hua X, et al. Female mice chimeric for expression of the simian virus $40 \mathrm{TAg}$ under control of the MISIIR promoter develop epithelial ovarian cancer. Cancer Res (2003) 63:1389-97.

62. Dinulescu DM, Ince TA, Quade BJ, Shafer SA, Crowley D, Jacks T. Role of K-ras and Pten in the development of mouse models of endometriosis and endometrioid ovarian cancer. Nat Med (2005) 11:63-70. doi:10.1038/ $\mathrm{nm} 1173$

63. Wu R, Hendrix-Lucas N, Kuick R, Zhai Y, Schwartz DR, Akyol A, et al. Mouse model of human ovarian endometrioid adenocarcinoma based on somatic defects in the Wnt/beta-catenin and PI3K/Pten signaling pathways. Cancer Cell (2007) 11:321-33. doi:10.1016/j.ccr.2007.02.016

64. Miyoshi I, Takahashi K, Kon Y, Okamura T, Mototani Y, Araki Y, et al. Mouse transgenic for murine oviduct-specific glycoprotein promoter-driven simian virus 40 large $\mathrm{T}$ antigen: tumor formation and its hormonal regulation. $\mathrm{Mol}$ Reprod Dev (2002) 63:168-76. doi:10.1002/mrd.10175

65. Kim J, Coffey DM, Creighton CJ, Yu Z, Hawkins SM, Matzuk MM. High-grade serous ovarian cancer arises from fallopian tube in a mouse model. Proc Natl Acad Sci U S A (2012) 109:3921-6. doi:10.1073/pnas.1117135109

66. Nikitin AY, Connolly DC, Hamilton TC. Pathology of ovarian neoplasms in genetically modified mice. Comp Med (2004) 54:26-8.

67. Vanderhyden BC, Shaw TJ, Ethier JF. Animal models of ovarian cancer. Reprod Biol Endocrinol (2003) 1:67. doi:10.1186/1477-7827-1-67

68. Lengyel E, Burdette JE, Kenny HA, Matei D, Pilrose J, Haluska P, et al. Epithelial ovarian cancer experimental models. Oncogene (2013). doi:10.1038/onc.2013. 321. [Epub ahead of print]

69. Mullany LK, Richards JS. Minireview: animal models and mechanisms of ovarian cancer development. Endocrinology (2012) 153:1585-92. doi:10.1210/en. 2011-2121

70. Mayer LP, Devine PJ, Dyer CA, Hoyer PB. The follicle-deplete mouse ovary produces androgen. Biol Reprod (2004) 71:130-8. doi:10.1095/biolreprod.103. 016113

71. Romero-Aleshire MJ, Diamond-Stanic MK, Hasty AH, Hoyer PB, Brooks HL. Loss of ovarian function in the VCD mouse-model of menopause leads to insulin resistance and a rapid progression into the metabolic syndrome. Am J Physiol Regul Integr Comp Physiol (2009) 297:R587-92. doi:10.1152/ajpregu. 90762.2008

72. Lohff JC, Christian PJ, Marion SL, Hoyer PB. Effect of duration of dosing on onset of ovarian failure in a chemical-induced mouse model of perimenopause. Menopause (2006) 13:482-8. doi:10.1097/01.gme.0000191883.59799.2e
73. Laviolette LA, Ethier JF, Senterman MK, Devine PJ, Vanderhyden BC. Induction of a menopausal state alters the growth and histology of ovarian tumors in a mouse model of ovarian cancer. Menopause (2011) 18:549-57. doi:10.1097/gme.0b013e3181fcalb6

74. Marion SL, Watson J, Sen N, Brewer MA, Barton JK, Hoyer PB. 7,12dimethylbenz[a]anthracene-induced malignancies in a mouse model of menopause. Comp Med (2013) 63:6-12.

75. Chodankar R, Kwang S, Sangiorgi F, Hong H, Yen HY, Deng C, et al. Cellnonautonomous induction of ovarian and uterine serous cystadenomas in mice lacking a functional Brcal in ovarian granulosa cells. Curr Biol (2005) 15:561-5. doi:10.1016/j.cub.2005.01.052

76. Hong H, Yen HY, Brockmeyer A, Liu Y, Chodankar R, Pike MC, et al. Changes in the mouse estrus cycle in response to BRCA1 inactivation suggest a potential link between risk factors for familial and sporadic ovarian cancer. Cancer Res (2010) 70:221-8. doi:10.1158/0008-5472.CAN-09-3232

77. Danilovich N, Roy I, Sairam MR. Ovarian pathology and high incidence of sex cord tumors in follitropin receptor knockout (FORKO) mice. Endocrinology (2001) 142:3673-84. doi:10.1210/endo.142.8.8320

78. Smith ER, Yeasky T, Wei JQ, Miki RA, Cai KQ, Smedberg JL, et al. White spotting variant mouse as an experimental model for ovarian aging and menopausal biology. Menopause (2012) 19:588-96. doi:10.1097/gme.0b013e318239cc53

79. Yang WL, Cai KQ, Smedberg JL, Smith ER, Klein-Szanto A, Hamilton TC, et al. A reduction of cyclooxygenase 2 gene dosage counters the ovarian morphological aging and tumor phenotype in Wv mice. Am J Pathol (2007) 170:1325-36. doi:10.2353/ajpath.2007.060769

80. Dubreuil P, Rottapel R, Reith AD, Forrester L, Bernstein A. The mouse W/c-kit locus. A mammalian gene that controls the development of three distinct cell lineages. Ann N Y Acad Sci (1990) 599:58-65. doi:10.1111/j.1749-6632.1990. tb42364.x

81. Nocka K, Tan JC, Chiu E, Chu TY, Ray P, Traktman P, et al. Molecular bases of dominant negative and loss of function mutations at the murine c-kit/white spotting locus: W37, Wv, W41 and W. EMBO J (1990) 9:1805-13.

82. Reith AD, Rottapel R, Giddens E, Brady C, Forrester L, Bernstein A. W mutant mice with mild or severe developmental defects contain distinct point mutations in the kinase domain of the c-kit receptor. Genes Dev (1990) 4:390-400. doi:10.1101/gad.4.3.390

83. Mintz B. Embryological development of primordial germ-cells in the mouse; influence of a new mutation, Wj. J Embryol Exp Morphol (1957) 5:396-406.

84. Murphy ED. Hyperplastic and early neoplastic changes in the ovaries of mice after genic deletion of germ cells. J Natl Cancer Inst (1972) 48:1283-95.

85. Murphy ED, Beamer WG. Plasma gonadotropin levels during early stages of ovarian tumorigenesis in the mice of the $\mathrm{Wx}-\mathrm{Wv}$ genotype. Cancer Res (1973) 33:721-3.

86. Bortvin A, Goodheart M, Liao M, Page DC. Dppa3/Pgc7/stella is a maternal factor and is not required for germ cell specification in mice. BMC Dev Biol (2004) 4:2. doi:10.1186/1471-213X-4-2

87. Sato M, Kimura T, Kurokawa K, Fujita Y, Abe K, Masuhara M, et al. Identification of PGC7, a new gene expressed specifically in preimplantation embryos and germ cells. Mech Dev (2002) 113:91-4. doi:10.1016/S09254773(02)00002-3

88. Olive KP, Tuveson DA, Ruhe ZC, Yin B, Willis NA, Bronson RT, et al. Mutant p53 gain of function in two mouse models of Li-Fraumeni syndrome. Cell (2004) 119:847-60. doi:10.1016/j.cell.2004.11.004

89. Smith ER, Yang WL, Yeasky T, Smedberg J, Cai KQ, Xu XX. Cyclooxygenase1 inhibition prolongs postnatal ovarian follicle lifespan in mice. Biol Reprod (2013) 89:103. doi:10.1095/biolreprod.113.111070

90. Cramer DW, Harlow BL, Titus-Ernstoff L, Bohlke K, Welch WR, Greenberg ER. Over-the-counter analgesics and risk of ovarian cancer. Lancet (1998) 351:104-7. doi:10.1016/S0140-6736(97)08064-1

91. Daikoku T, Wang D, Tranguch S, Morrow JD, Orsulic S, DuBois RN, et al. Cyclooxygenase- 1 is a potential target for prevention and treatment of ovarian epithelial cancer. Cancer Res (2005) 65:3735-44. doi:10.1158/0008-5472. CAN-04-3814

92. Schildkraut JM, Moorman PG, Halabi S, Calingaert B, Marks JR, Berchuck A. Analgesic drug use and risk of ovarian cancer. Epidemiology (2006) 17:104-7. doi:10.1097/01.ede.0000190538.55645.f8

93. Sorensen HT, Friis S, Norgard B, Mellemkjaer L, Blot WJ, McLaughlin JK, et al. Risk of cancer in a large cohort of nonaspirin NSAID users: a population-based study. Br J Cancer (2003) 88:1687-92. doi:10.1038/sj.bjc.6600945 
94. Ness RB, Cottreau C. Possible role of ovarian epithelial inflammation in ovarian cancer. J Natl Cancer Inst (1999) 91:1459-67. Response in: J Natl Cancer Inst (2000) 92:163. doi:10.1093/jnci/91.17.1459

95. Smith ER, Daly MB, Xu XX. A mechanism for Cox-2 inhibitor antiinflammatory activity in chemoprevention of epithelial cancers. Cancer Epidemiol Biomarkers Prev (2004) 13:144-5. doi:10.1158/1055-9965.EPI-461-2

96. Smith ER, Xu XX. Etiology of epithelial ovarian cancer: a cellular mechanism for the role of gonadotropins. Gynecol Oncol (2003) 91:1-2. doi:10.1016/ S0090-8258(03)00463-3

97. Bhavnani BR, Strickler RC. Menopausal hormone therapy. J Obstet Gynaecol Can (2005) 27:137-62.

98. Hammond GL, Rabe T, Wagner JD. Preclinical profiles of progestins used in formulations of oral contraceptives and hormone replacement therapy. Am J Obstet Gynecol (2001) 185:S24-31. doi:10.1067/mob.2001.117415

99. Walker GR, Schlesselman JJ, Ness RB. Family history of cancer, oral contraceptive use, and ovarian cancer risk. Am J Obstet Gynecol (2002) 186:8-14. doi:10.1067/mob.2002.118657

100. Tung KH, Wilkens LR, Wu AH, McDuffie K, Nomura AM, Kolonel LN, et al. Effect of anovulation factors on pre- and postmenopausal ovarian cancer risk: revisiting the incessant ovulation hypothesis. Am J Epidemiol (2005) 161:321-9. doi:10.1093/aje/kwi046

Conflict of Interest Statement: The authors declare that the research was conducted in the absence of any commercial or financial relationships that could be construed as a potential conflict of interest.

Received: 30 October 2013; accepted: 12 February 2014; published online: 26 February 2014.

Citation: Smith ER, Wang Y and Xu X-X (2014) Development of a mouse model of menopausal ovarian cancer. Front. Oncol. 4:36. doi: 10.3389/fonc.2014.00036

This article was submitted to Women's Cancer, a section of the journal Frontiers in Oncology.

Copyright (C) 2014 Smith, Wang and Xu. This is an open-access article distributed under the terms of the Creative Commons Attribution License (CC BY). The use, distribution or reproduction in other forums is permitted, provided the original author (s) or licensor are credited and that the original publication in this journal is cited, in accordance with accepted academic practice. No use, distribution or reproduction is permitted which does not comply with these terms. 